\title{
O romance em Angola: ficção e história em Pepetela
}

Giselle Larizzatti Agazzi*

O crítico uruguaio Ángel Rama elege o romance dentre os outros gêneros como o que melhor se presta a pensar as relações entre literatura e sociedade, porque veicula as ideologias, os valores e o imaginário das sociedades em que foi gerado:

Para um escritor, em especial um romancista - em quem continua estimulando misteriosamente a vocação de competir com o registro civil e, por que não?, com o próprio Deus -, a literatura é realidade, a sua e, portanto decreta-a para todos os demais homens; realidade justificante, a literatura é ele. Contra a fórmula depreciativa "e o resto é literatura", afirma-se que esse resto é o próprio homem que escreve. Nessa avassaladora dependência do ser escritor, não se deve ver uma nova exaltação romântica do mistério da criação, nem da infinidade insipiradora, mas a vocação do ofício bem cumprido como modo de inserirse e justificar-se dentro da sociedade, porque as explicações dadas de diferentes ângulos sobre essa zona da vocação convergem para ambos os pontos (RAMA, 2001, p. 107).

Segundo Rama (2001), a forma romanesca, direta ou indiretamente, é portadora do contexto em que foi pensada e engendra, ficcionalmente, a partir da construção do foco narrativo, dos personagens, do tempo e do espaço, marcas capazes de dar pistas ao público leitor sobre os nexos de causalidade histórica (ainda, ou principal- 
mente, quando esses faltam no plano literário) e sobre as relações sociais estabelecidas na realidade. O romancista revela-se, assim, como um porta-voz do momento em que elabora o texto, responsabilizando-se por escolher e elaborar um ou mais pontos de vista sobre a História.

As narrativas de Artur Carlos Maurício Pestana dos Santos, depois batizado de Pepetela nas frentes de guerrilha, respondem a essa perspectiva ao percorrer os meandros históricos de Angola. Nascido em Benguela, a 29 de outubro de 1941, publicou - e ainda está a publicar - diversos romances, peças teatrais e contos, alguns dos quais já bastante divulgados e lidos. Representante de uma geração comprometida com a luta pela independência do país e pela construção de uma sociedade igualitária, compartilha do projeto intelectual vislumbrado por personalidades - como a do primeiro presidente de Angola livre, Agostinho Neto - que entendem a cultura poder projetar e provocar transformações sociais. Em entrevista, Pepetela afirma:

Creio que a literatura nacional é elemento indispensável, tão importante como outro qualquer, para a consolidação da independência. É um fator que ajuda a aumentar a unidade nacional, por ser veículo de situações, modos de vida e de pensar, dentro do País, (...) Pode ser exagero - é caso para se discutir - mas afirmo que não há, não pode haver, a criação dum país verdadeiramente independente sem uma literatura nacional própria, que mostre ao povo aquilo que o povo sempre soube: isto é, que tem uma identidade própria (SALGADO, 2000, p. 303).

Entre seus precursores, estão Assis Júnior, com O segredo da morta (1934), e Castro Soromenho, com, entre outros, Terra morta (1949), que anunciam a intenção de formar uma literatura segundo inflexões angolanas, ao incorporarem os elementos culturais da terra e do período. Essa tendência predominará após os anos de 1950 , isolando a atividade de escritores como Óscar Ribas, que, segundo a crítica Rita Chaves, tem seu repertório "centrado na informação e não na experiência: o conhecimento dos componentes da cultura examinada resulta de investigação e não de familiaridade com o meio (CHAVES, 1999, p. 153). 
A partir do fim da segunda guerra mundial, seguindo os protestos dos países africanos colonizados pela Inglaterra e França, de movimentos internacionais como o da Negritude, as rupturas com Portugal são cada vez mais reivindicadas pela população angolana. À época, também o jornalismo e a poesia conclamam a construção de uma tradição cultural autônoma e independente e lançam as bases do movimento Vamos descobrir Angola!, que funda, em 1950, o espaço em que o romance se desenvolverá para cumprir, segundo Bakhtin, seu destino de gênero flexível, sem fôrma fixa e de incontáveis possibilidades de escritura, porque:

é o único gênero por se constituir, e ainda inacabado. As forças criadoras do gênero romancesco realizam-se sob a plena luz da História. A ossatura do romance enquanto gênero ainda está longe de ser consolidada, e não podemos ainda prever todas as suas possibilidades plásticas (BAKHTIN, 1998, p. 397).

Os movimentos nacionalistas marcaram a história literária dos países africanos de língua portuguesa e prepararam o ambiente cultural para o surgimento das narrativas de Pepetela, responsáveis por transculturar ${ }^{1}$ o gênero romance para as terras angolanas ao lado de importantes nomes como Luandino Vieira, Baltasar Lopes e Mia Couto. Do encontro entre as duas culturas, a da metrópole e a da colônia, surgia, assim, uma literatura genuinamente angolana, que negava as tendências "colaboracionistas" - para usar uma expressão de Alfredo Margarido (MARGARIDO, 1980, p. 459) - dos primeiros escritores com as políticas imperialistas sem, entretanto, desprezar suas manifestações culturais.

Ao buscar a afirmação dos valores nacionais, os livros de estréia de Pepetela debruçaram-se sobre as muitas identidades angolanas. Contando com mais de uma dezena de romances até o momento, o escritor parece confirmar a tese de Bakhtin de que a ossatura do romance enquanto gênero ainda está longe de ser consolidada (BAKHTIN, 1998), dado que seus últimos títulos adotam a ironia como eixo estruturador, afastando-se do realismo histórico das primeiras publicações. O resultado, a partir dos anos de 1990, é a construção de romances que parodiam as relações sociais ango-

\footnotetext{
1 "Transculturar" é o termo que o crítico uruguaio Ángel Rama utiliza para designar as obras literárias que surgem da incorporação e transformação dos aspectos de duas culturas distintas postas em contato. Tais textos engendram uma literatura genuinamente nacional, porque apresentam características próprias, ao serem forjadas segundo as inflexões locais, reveladas nas escolhas temáticas e, fundamentalmente, estéticas (RAMA, 2001).
} 
lanas, as utopias revolucionárias dos anos pré-independência, as intermináveis disputas de poder, os tipos corruptos e, ao fim, até algumas das narrativas que publicou (já que essas projetavam imagens que serão corrompidas pela ironia aguda do autor).

De dentro da ação revolucionária (participou ativamente da guerra pela independência de Angola, vindo a assumir posteriormente importantes cargos políticos) e do universo literário, Pepetela faz ressoar as vozes dos angolanos através das quais procura construir, ao lado de outros intelectuais, uma literatura autônoma, cuja existência de escritores, de um conjunto de receptores e da obra formam o que Antonio Candido definiu como "sistema":

O conjunto dos três elementos dá lugar a um tipo de comunicação inter-humana, a literatura, que aparece sob este ângulo como um sistema simbólico, por meio do qual as veleidades mais profundas do indivíduo se transformam em elementos de contacto entre os homens, e de interpretação das diferentes esferas da realidade (CANDIDO, 1997, p. 23).

E é como sistema simbólico que seus livros acompanham os anos pré e pós-independência de Angola, em 1975, e descrevem o movimento que vai da utopia revolucionária à profunda melancolia da geração que entreviu a formação de uma sociedade plenamente autônoma. A percepção crescente de que as projeções do passado não vingaram determina as escolhas ficcionais de Pepetela, que gradativamente troca o olhar sobre a construção do revolucionário de esquerda pelo olhar crítico sobre os compatriotas, que aprenderam os modos imperialistas de ser e de agir. Segundo a crítica Inocência Mata, da Universidade de Lisboa,

(...) a sua singularidade reside no questionamento do Presente (valores, comportamentos, idéias) a partir das mitificações (às vezes das falsificações) da História. Como um mago, Pepetela vai-nos desvelando os vários trilhos de memórias do Passado, vai-nos conduzindo pela percepção da História como um processo feito de cruzamento de olhares diferentes sobre o mesmo" (MATA, www.geocites.com/ail_br/pepetelaeasnovas margens.html). 
Ganhador de prêmios como o Camões (1997) pelo conjunto de sua obra, entre os romances de Pepetela estão As aventuras de Ngunga (1973), Muana Puó (1978), Mayombe (1980), Yaka (1988), A geração da utopia (1992), O desejo de Kianda (1995), Parábola do cágado velho (1996), Jaime Bunda, agente secreto (2001). Seu tom cada vez mais crítico à realidade nacional evidenciou-se a partir dos anos de 1990, quando já forjava o olhar atento e vigilante dos que ocuparam o poder no pós-independência. O último romance publicado, Predadores (2005), em tom de farsa, debocha da elite política, econômica e intelectual angolana, e aponta para a continuidade dos mecanismos de opressão no país.

A renovação da sua obra parece acompanhar a contínua reconstrução da perspectiva crítica desse intelectual interessado em percorrer os meandros históricos de Angola. Buscando iluminar como se degradou o imaginário utópico dos anos revolucionários, seus personagens mais recentes, em oposição aos dos primeiros romances, experimentam a corrosão das relações interpessoais, da comunidade e dos meios de comunicação imersos que estão na própria individualidade e em atos de corrupção.

Não a quantidade de romances, mas principalmente a relevância literária dos mesmos, leva críticos como Rita Chaves a afirmarem que:

ele é hoje o único nome quase que exclusivamente identificado com o romance como forma de expressão. Associado ao mundo da escrita, esse gênero literário exerceu desde sempre uma impressionante atração sobre os escritores angolanos, em que pese a sua inserção num universo cultural marcado pela tradição oral. A despeito desse fascínio, a obra de seus companheiros, como José Luandino Vieira, Arnaldo Santos, Costa Andrade, Manuel Rui, Henrique Abranches, entre outros, divide-se entre contos e romances, romances e poemas, poemas e contos (CHAVES, 2005, 86).

A primeira narrativa de inesperado sucesso de Pepetela, que atuava nas frentes de combate do Movimento de Libertação de Angola à época das lutas pela independência ao mesmo tempo em que 
elaborava dois de seus romances, é um curto texto, As aventuras de Ngunga, cujo cunho pedagógico evidencia o comprometimento do autor com a causa angolana. Escrito para servir de texto às crianças e adultos em alfabetização nas escolas do MPLA das zonas libertadas, o livro apresenta capítulos breves e linguagem simples e acessível ao público-alvo.

Conhecendo a mentira, a falsidade, o jogo de interesses, o protagonista, o pequeno Ngunga, avalia o comportamento dos adultos e escolhe seu próprio caminho, buscando afirmar-se em um mundo pautado por ações injustas, vindas, tantas vezes, também de alguns companheiros revolucionários, corrompidos pela ação colonial ao longo dos séculos. A história do menino órfão - que conhece vários tipos de pessoas e diversos lugares, passa por inúmeras dificuldades, supera obstáculos, nega a corrupção e a luta pelo poder - narra a formação do genuíno revolucionário de esquerda, comprometido com a ética de vocação coletiva:

Se Ngunga está em nós, que esperamos então para fazer crescer? Como as árvores, como o massango e o milho, ele crescerá em nós se o regarmos. Não com água do rio, mas com ações. Não com água do rio, mas com o que Uassamba em sonhos oferecia a Ngunga: a ternura (PEPETELA, 1983, p. 58).

A criança torna-se um herói nacional e preconiza o que deveria ser o novo homem angolano, comprometido com a construção de relações sociais justas, pautadas na transformação dos vínculos opressores, do preconceito racial e de quaisquer formas de violência, inclusive as herdadas da própria tradição nacional. Ngunga é, assim, uma espécie de ícone dos anseios revolucionários. Fala o escritor angolano Jofre Rocha em 1984 sobre o período:

A luta armada não calou a voz dos poetas e contistas, antes, pelo contrário, no próprio fragor dos combates se forjaram novos escritores (...) São vozes harmoniosas que em nome da sagrada esperança da libertação conclamam os homens à luta e fazem convergir todos os esforços na mesma direção" (ROCHA, 2004, p. 31). 
As particularidades históricas do continente africano não são desprezíveis, quando se pensa que a colonização, a escravidão e o neoliberalismo direcionaram a ação dos grupos sociais. A diáspora e as conseqüências do preconceito contra os negros não são comentários laterais à história do país. Ao contrário, devem ser considerados como determinantes das condições miseráveis de vida que os países africanos de língua portuguesa ainda enfrentam. Diz Fanon:

Os negros são comparação. Primeira verdade. Eles são comparação, isto é, eles se preocupam constantemente com o ideal do Eu. Cada vez que estão em contacto com um outro fala-se de valor, de mérito. (...) Qualquer posição ou fixação de si mantém relações de dependência com a destruição do outro. É sobre ruínas dos que me circundam que construo minha virilidade" (FANON, 1983, p. 172).

Para Pepetela, intelectual branco, atualmente professor de Sociologia na Faculdade de Arquitectura de Luanda, a empreitada é ainda maior, dado que, depois de 1975, muitos se uniram em torno das vantagens oferecidas pelo capital e não da "virilidade" africana em oposição ao preconceito racial a que se refere Fanon. Desse constante "questionamento" da História, é que aparecem os múltiplos pontos de vista que a obra constrói, apontando para a complexa convivência entre diferentes comunidades africanas, que se defrontaram nos anos pré e pós independência com o desafio de construir a identidade nacional. O conceito de Nação não é, como se sabe, natural do continente, recortado na mesa dos colonizadores para dividir os ganhos com a exploração das terras:

Querem hoje que eu seja tribalista?

De que tribo? pergunto eu. de que tribo, se eu sou de todas as tribos, não só de Angola, como de África? Não falo eu o swahili, não aprendi eu o haussa com um nigeriano? Qual é a minha língua, eu, que não dizia uma frase sem empregar palavras de línguas diferentes? 
Agazzi, G. L. O romance em Angola: ficção e história em Pepetela

E agora, que utilizo para falar com os camaradas, para deles ser compreendido? O português. A que tribo pertence a língua portuguesa?

Eu sou o que é posto de lado porque não seguiu o sangue da mãe kimbundo ou o sangue do pai umbundo. Também Sem Medo, também Teoria, também o Comissário, e tantos outros mais. (...) (PEPETELA, 1982, p. 138).

Essa tentativa de abarcar a maior parte possível de modos de ver o mesmo fato faz ressoar a origem mesma dessa terra de Angola, marcada pela pluralidade de etnias, que tiveram de forçosamente aceitar conceitos como os de Estado Nação. Domingos Van-Dúnem e Ruy Burity da Silva, em Breves notas sobre a integração cultural em Angola, apontam para problemática tão complexa por ocasião da VI Conferência dos Escritores Afro-Asiáticos:

A redescoberta da personalidade e identidade nacional, o nosso "voltar a ser independente em novas condições", impõe a introdução urgente da recente política cultural, de acordo com as nossas opções ideológicas, que deverá ser revestida das condições exigidas a um termômetro, pois todos nós sabemos o quanto se torna necessário acautelar conflitos, intrínsecos das fases de mudança e, aqui entre nós, sempre na iminência das perturbações ocasionadas pela diferenciação de origem sóciocultural e meios acadêmicos, que influenciaram a formação da actual família nacional (VAN-DÚNEM, 1981, p.158).

É esse o lugar de que escreve Pepetela. Entretanto, para unir as vozes em luta, primeiro pela expulsão dos portugueses, depois pela autonomia internacional, foi necessário recuperar o comum e produzir a idéia da coletividade angolana. Seguindo Inocência Mata, essa é a árdua tarefa que, ao que apontam os romances de Pepetela, ainda se deve cumprir:

"Nessa busca na história de matéria ficcional sobressai a sua insistência em histórias de deslocamentos, de fundação e de reterritorializações. Fá-lo para recuperar outros segmentos identitários que, porque da margem, necessitam de celebrar a sua temporalidade e a sua memória. Outrossim, porque uma das 
dominantes da identidade é a sua historicidade, o autor intenta incluir uma colectividade segmentaria nessa busca, através de uma experiência individual, elegendo-a como alegoria nacional: a nação, agora, faz-se de muitas particularidades, muito diferentes (MATA, www.geocites.com/ail_br/pepetelaeasmargens.html).

O projeto de nação, feita a partir de "muitas particularidades, muito diferentes" disputa com a história de Angola, feita de incontáveis dissensões e guerras civis. Depois do violento processo de independência, os embates ao longo do território fizeram mais de dois milhões de mortos, contabilizando quase quarenta anos de disputas armadas. Entre 1961, quando se iniciaram as lutas pela independência, até 2002, quando, depois de muitas tentativas de paz, os últimos confrontos aconteceram, aprofundaram-se as miseráveis condições de vida da população, a despeito das riquezas minerais da terra.

Construir a identidade nacional exige esforços, dos quais derivam os textos de Pepetela, que buscam recompor a memória do povo ora contando a história contemporânea ao próprio momento da escrita ora resgatando o passado como o faz Yaka. Nesse romance, o autor percorre os conflitos vividos por várias gerações de colonos portugueses, que tentam, entre 1890 e 1975, a ascensão econômica enquanto assistem à gradativa desagregação do núcleo familiar. Para tanto, muitos símbolos são construídos e retomados como a imagem já tradicional na literatura angolana do idoso que se encontra à margem da família, sendo completamente alijado do contexto do qual participa (também a literatura moçambicana com autores como Mia Couto faz inúmeras referências ao abandono do idoso, que vem a representar a rejeição dos aspectos da cultura tradicional pelas novas gerações).

A dissolução dos laços familiares em Yaka é mostrada como parte das graves conseqüências da ação colonialista, que conseguiu, a partir de ações violentas, desagregar os vínculos interpessoais pautados na solidariedade e amizade. Em lugar da fraternidade, sustentáculo da própria noção de comunidade, surgem os interesses pessoais e a afirmação individual: 
Agazzi, G. L. O romance em Angola: ficção e história em Pepetela

- Por que não conversam sobre outras coisas? - interrompeu Glória.

- Não há nada mais para conversar, mãe - disse Xandinho. - Só isso. Trata-se da nossa vida. Acho que são todos iguais e qualquer que seja o Movimento que fique no Governo vai-me lixar. Sem ter em consideração os anos que trabalhei para esta terra, a abrir estradas, a organizar recenseamentos, a cobrar impostos, etc. Tudo isso era para o bem do País, ou não?

- Para bem do colonialismo - disse Olívia - Tens de distinguir as coisas (PEPETELA, 1988, p. 322).

Para o angolano Eugénio Ferreira, Yaka mostra o empenho de Pepetela em colocar-se ao lado de escritores que "olharam menos para o gesto estudado dos reis e dos dirigentes da República do que para os movimentos mais obscuros, mas também mais profundos e por isso significativos, da grei laboriosa que há nos povos" (FERREIRA, 1989, p. 75).

Mas é no início dos anos de 1990 que Pepetela, com A geração da utopia, inicia um balanço crítico do movimento revolucionário e da condução política do país, apontando para os impasses dos que fizeram a independência sem, entretanto, mudar significativamente as relações de poder existentes antes de 1975:

- Tens razão - disse o Sábio. - O mais importante para uma geração é dar qualquer coisa de bom à seguinte, um projecto, uma bandeira. No fundo, é o pai a deixar uma herança para o filho. E é triste sentir que a nossa geração, que vos deu apesar de tudo a independência, logo a seguir vos tirou a capacidade de a gozar. Como o pai que, ao oferecer um brinquedo ao filho, o monopoliza, só ele brinca com ele, com o pretexto de que o filho o vai estragar. Não é mesmo tragicabsurdo?

- Vocês são demasiado negativos em relação a tudo - disse Sara. - Está bem, houve erros. Mas nem tudo foi mau, como agora se diz. E não nos deixaram fazer o que queríamos, houve sempre pressões externas impeditivas. Dum lado ou doutro, é preciso que diga (PEPETELA, 1995, p. 304). 
Impossibilitado de fazer um pacto nacional de paz entre os vários grupos nacionais, o MPLA passou a abrigar disputas internas pelo poder e distanciou-se do discurso revolucionário, utópico, das décadas anteriores ao movimento. É Sara que, diante dos rasgos melancólicos que pontuam as falas dos personagens, denuncia o que tenta ocultar-se de modo grosseiro: as conseqüências da Guerra Fria, da política sul-africana, enfim, das pressões internacionais e imperialistas sobre o país. Entre tantas contradições históricas, $A$ geração da utopia desenvolve-se segundo as vozes testemunhais que analisam lucidamente os fatos, procurando encontrar os nexos causais que levaram a nação ao caos social e político. De todos os lados, os personagens tentam compreender os fatos passados:

Começa a ser tempo de se fazer a História disto tudo - disse Orlando. - Como uma geração faz uma luta gloriosa pela independência e a destrói ela própria. Mas parece que a gente da sua geração não é capaz de a fazer. $E$ a minha geração, a dos que agora têm trinta anos, não sei. Fomos castrados à nascença. Eu tinha treze anos quando Luanda se mobilizou em massa para receber os heróis da libertação. Vivíamos para aquilo. (...) E depois quiseram enquadrar-nos. Disseram, devem marchar como os soldados, vocês são frutos dos soldados. (...) Liquidaram a imaginação, em nome duma moral militarista, de disciplina de caserna ou de convento, não sei, já não se podia criticar, dizer o que se pensava, tinha de se pensar antes de se dizer. Houve lutas internas, golpes de palácio que ninguém entendia, afastamentos de tipos que para nós eram heróis, outros iam parar à cadeia. E a minha geração, jovem e entusiasmada, foi perdendo o entusiasmo (...) (PEPETELA, 1995, p. 304).

O leitor de Pepetela conhece, assim, a história de uma geração de angolanos, a partir do ponto de vista dos que iam então vencidos até os anos de 1970 e que acreditaram terem alterado o curso da História com a independência, passando a vencedores. De fato, houve a independência e o MPLA assumiu o governo. Entretanto, o que os romances de Pepetela mostram é que, em alguns anos, os revolucionários reconheceram que as ações não foram suficientes para tornar a nação autônoma. 
Agazzi, G. L. O romance em Angola: ficção e história em Pepetela

A utopia que motivara o processo revolucionário mostra-se, assim, vazia de sentido em um contexto em que o vencido permanece sendo o povo, que, aliás, aprendeu a reproduzir as redes de corrupção na sua própria comunidade. Apreendendo, cada vez com ironia mais aguda, o que Pepetela chama de "modos de vida e de pensar" da sociedade angolana, seu trabalho de arqueólogo ilumina as origens dos traumas históricos para, fazendo-os conhecidos, redimi-los.

Ao remexer incansavelmente nas ruínas da história, o autor também encontra a força e integridade do povo angolano, soterrada por anos de opressão e violência, como nos mostra Nacib, único entre os personagens de Predadores (2005) que contraria a tendência dominante ao manter os vínculos com seu grupo social de origem e negar qualquer tipo de corrupção apesar de ter ingressado na nova burguesia angolana.

A sensação de castração "à nascença" é o mote das últimas narrativas do autor, inquietantes para o leitor de Pepetela, por desenvolver não mais as profundas marcas de uma melancolia histórica, da qual, para Ernildo Stein, em Órfãos da Utopia, poderia advir mais uma vez a utopia depois de e se operado o luto pelas perdas:

A queda da utopia socialista faz com que surja uma espécie de vontade política nova. Construir uma possível transformação, uma possível emancipação a partir de elementos de ideais que se coordenem em torno das possibilidades de racionalidade que a humanidade apresenta. Articular um futuro com os recursos que se apresentam nas formas de reflexão das ciências humanas e na forma de análise da filosofia (STEIN, 1996, p. 69).

Essa brecha a que se refere o filósofo brasileiro não encontra eco em Jaime Bunda, agente secreto. Misto de paródia do romance policial e do romance realista, o herói é destituído da ética de vocação coletiva, que possibilitara, nos tempos de colônia, a construção de projetos de sociedades justas, igualitárias e fraternas:

A luta política das esquerdas era feita através de uma aposta numa moral futura como regra, que levaria a uma identificação entre moral individual e moral coletiva. Esta identificação resul- 
taria da humanização da natureza e a naturalização do homem. Era a reconciliação entre natureza e história, que significaria o desaparecimento da moral individual burguesa. O caráter coletivo teria, necessariamente, um caráter social, pois todos se orientariam a partir de um modelo de sociedade justa, harmonizada, sem classes (STEIN, 1996, p. 73).

O protagonista de Jaime Bunda veicula o imaginário exatamente oposto ao que contemplaria o "desaparecimento da moral individual burguesa”. Anti-herói por convicção, Jaime é um estagiário tido como inútil, reconhecido por sua "bunda portentosa", que lhe atrasa os movimentos e atrai a curiosidade alheia. Diante de um crime a ser desvendado, ou melhor, encoberto, ele é chamado a ter sua primeira atuação como detetive do chefe Bunker, homem misterioso que ninguém conhece, mas a que todos temem. O Bunda deve descobrir quem é o assassino de uma menina de quatorze anos. Enquanto procura pistas, conhece outros crimes (lavagem de dinheiro, favorecimentos, vinganças pessoais), todos são, ao final, ignorados, a fim de que se mantenha o pacto das relações de poder e de corrupção, das quais o estagiário passa a fazer parte.

Mais uma vez, o crime maior não é contra uma pessoa, mas contra a nação: o povo é a vítima das várias formas de opressão que as elites locais exercem junto a aqueles que elas cooptam dentre a população ávida por poder. Os homens incriminados não são dois inocentes, mas não são os verdadeiros assassinos; e o detetive que conduz as investigações é o criminoso, o Estado constituído. O jogo de peças trocadas denuncia, seguindo a tradição dos romances de Pepetela, a completa ausência de ética nas relações, determinadas por disputas por poder e dinheiro: "Jaime Bunda, o verdadeiro herói da noite, encheu o peito. Cada vez se sentia mais perto do Poder, aquele que cria e espezinha tudo à sua volta (PEPETELA, 2003, p. 296).

Em uma trama contada por dois narradores que se alternam, um homem e uma mulher, e pela voz do autor interno, que intervém como crítico de seus alter-egos, a história forja um representante desta geração cuja virilidade, para usar um termo de Fanon, fora 
Agazzi, G. L. O romance em Angola: ficção e história em Pepetela

perdida ao longo dos anos da diáspora. Longe de ser um investigador com lances intuitivos e criativos de mestre, o Bunda é leitor voraz e admirador dos best-sellers policiais norte-americanos, apesar de ter herdado de seu pai uma pequena biblioteca com clássicos universais:

O pai de Jaime (...) repetia sempre tenho vergonha de dizer que sou primo deste ou daquele para conseguir qualquer coisa, obtendo porque valho, senão recuso, era um intelectual, no fundo o teu pai era um intelectual embora sem tantos estudos assim, gostava de ler e de saber coisas, se contentava com o emprego sem futuro onde foi cair no tempo colonial (...) ficou conformado, chupando o cachimbo e lendo os seus livros, será que ele escrevia? Jaime Bunda não sabia, nunca tinha visto o pai com algum caderno onde apontasse poemas ou outra coisa, gostava era mesmo de ler e Ihe passou o hábito, mas Bunda foi ficando pelos policiais. Tinha no quarto alguns livros do pai, enciclopédias e romances, no entanto tinha desistido deles, muito cansativos, melhor eram mesmo os policiais americanos, os seus grandes mestres (PEPETELA, 2003, p. 61).

O anti-herói, assimilado, defensor do ideário capitalista, de índole violenta, não "suja as mãos", porque não gosta de bater nos outros, mas não está distante dos que gostam, porque tem prazer em ver os outros apanharem e não hesita em contratar um matador para o marido da sua amante.

De ética tão volúvel quanto individualista, o narrador abandona o leitor à deriva, impedindo-Ihe o conforto de identificar-se com quaisquer dos personagens. Até mesmo o pai de Bunda, já morto, que fora abandonado na periferia de Luanda e perseguira uma postura ética e alinhada com a revolução, exime-se de contribuir efetivamente com a luta pela independência. Entre os extremos da passividade e da atividade corrupta, o romance não apresenta outra possibilidade de inserção social.

Assim, em Jaime Bunda - agente secreto, a utopia não vibra. Tampouco a melancolia. O que se lê é o completo ceticismo diante de uma realidade que só pode ser contada pela paródia se se quiser 
alcançar os movimentos dos grupos de poder internacionais, que praticam políticas neoliberais criminosas, embora se coloquem como vítimas do processo histórico.

Desse estado letárgico, ainda assim, surge o esforço do escritor na sua intensa busca de captar pela linguagem os desvios que nos conduzem a repetir as práticas criminosas em nosso cotidiano. É urgente conhecer os intrincados aspectos históricos e os jogos de interesses de um país que caiu no esquecimento das grandes mídias exatamente por expor de modo brutal o estado de barbárie contemporâneo.

A letra do escritor não trai seu passado de luta e afirma a ética de vocação coletiva, fazendo com que o leitor se lembre de que ainda há um projeto a ser imaginado. Entretanto, para gerá-lo, é preciso reconstruir a memória dos significados de justiça e igualdades sociais. É possível que o tempo da geração revolucionária de Pepetela tenha passado. E que a utopia, agora, germine na elaboração do luto pelo fim daqueles anos. Ao menos, os esforços do escritor provocam o leitor a lembrar de que os envelhecidos projetos de construção de uma sociedade justa e igualitária fazem parte da história da humanidade. Portanto, é possível, ainda, apostar em outros devir que não os atuais.

Resumo: A formação do romance em Angola dialoga com a formação da própria nação angolana. Ficção e História mantêm, assim, estreita relação, que pode ser conhecida através da obra de Pepetela, um dos escritores mais importantes do país desde os anos que antecederam a independência. $O$ que se pretende neste texto é apontar para como as suas narrativas, lidas em conjunto, descrevem, temática e esteticamente, um movimento que oscila entre as perspectivas revolucionárias e a mais profunda melancolia, experimentada com a falência do projeto de construção de uma sociedade justa e igualitária. A fim de iluminar o imaginário social veiculado pelos romances de Pepetela, tem-se a crítica de cultura materialista como referencial teórico. 
Palavras-chave: Angola, ficção, história, romance, Pepetela.

\begin{abstract}
The novel formation in Angola dialogues with the formation of the Angolan nation itself. Fiction and History keep, thus, a narrow relation, which can be known through the works of Pepetela, one of the most important writers in the country since the years that preceded independence. This text intends to point to the way how his narratives, read in set, describe thematically and esthetically a movement that oscillates between the revolutionary perspectives and the deepest melancholy, tried with the bankruptcy of the project for the construction of a fair and egalitarian society. In order to illuminate the social imaginary propagated by the Pepetela's novels, the critique of materialistic culture is adopted as the theoretical reference.
\end{abstract}

Key words: Angola, fiction, history, novel, Pepetela.

Resumen: La formación del romance en Angola dialoga con la formación de la propia nación angolana. Ficción e História se mantienen en estrecha relación, y puede ser conocida a través de la obra de Pepetela, uno de los escritores más importantes del país desde los años que precedieron a la independencia. Este texto pretende apuntar para sus narrativas que, leídas en conjunto, describen, temática y esteticamente, un movimiento que oscila entre las perspectivas revolucionarias y la más profunda melancolía, experimentada con la falencia del proyecto de construcción de una sociedad justa e igualitaria. La crítica de cultura materialista es el referencial teórico que ilumina el imaginario social vehiculado por los romances de Pepetela.

Palabras clave: Angola, ficción, historia, romance, Pepetela. 


\section{Bibliografia}

AGUIAR, F.; VASCONCELOS, S. (Org). Angel Rama. Literatura e cultura na América Latina. São Paulo, EDUSP. 2001. p. 47-110.

BAKHTIN, M. Questões de literatura e de estética - A teoria do romance. 4a. ed., São Paulo: Edunesp, 1998.

CANDIDO, A. Formação da literatura brasileira. Belo Horizonte, Rio de Janeiro: Itatiaia, 1997.

CHAVES, R. A formação do romance angolano: entre intenção e gestos. São Paulo, Universidade de São Paulo: Via Atlântica, 1999.

Angola e Moçambique: experiência colonial e territórios literários. São Paulo: Ateliê Editorial, 2005.

FANON, F. Pele negra. Máscaras Brancas. Rio de Janeiro, Outra gente: Fator, 1983.

FERREIRA, E. Espiral literária. União dos Escritores Angolanos, 1989. MARGARIDO, A. Estudos sobre literaturas das nações africanas de língua portuguesa. Lisboa: A regra do jogo, 1980.

MATA, I. Disponível em: <www.geocites.com/ail_br/pepetelaeasnovas margens.html>

PEPETELA. Mayombe. Lisboa, Edições 70, 1982. . As aventuras de Ngunga. 3 ed., São Paulo: Ática, 1983. . Yaka. Lisboa, União dos Escritores de Angola, 1988. A geração da utopia. Lisboa, Dom Quixote, 3 ed., 1995. Jaime Bunda - agente secreto. Rio de Janeiro, Record, 2003.

RAMA, À. Dez problemas para o romancista latino-americano. In: AGUIAR, F.; VASCONCELOS, S. (Org.). Angel Rama. Literatura e cultura na América Latina. São Paulo, EDUSP. 2001. p. 47-110.

ROCHA, J. Intervenções sobre literatura, artes e cultura. Luanda: Editorial Kilombelombe, 2004.

SALGADO, T. e SEPÚLVEDA, M. do C. África e Brasil: letras e laços. Rio de Janeiro: Atlântica, 2000.

STEIN, E. Órfãos de utopia: A melancolia da esquerda. 2 ed., Porto Alegre: UFRGS, 1996. 
Agazzi, G. L. O romance em Angola: ficção e história em Pepetela

VAN-DÚNEM, D. e SILVA, R. B. Breves notas sobre a integração cultural em Angola. In: Documentos da VI Conferência dos Escritores Afro-Asiáticos. Teses Angolanas. Lisboa: Edições 70/União dos Escritores Angolanos, 1981.

e-mail: giselleagazzi@terra.com.br

Recebido em 24/08/2006.

Aceito em 27/09/2006. 